\title{
Optimismo católico ante el dolor Barroco: Paraphrasis in Iob de Jerónimo Osório ${ }^{1}$
}

\author{
Manuel Lázaro Pulido²
}

Recibido: 16 de marzo de 2017 / Aceptado: 04 de febrero de 2018

Resumen. El dolor, como la melancolía, es un sentimiento barroco nacido de la crisis del Mundo. Jerónimo Osório, uno de los mayores intelectuales barrocos del pensamiento portugués, presenta la figura bíblica de Job como paradigma de la respuesta católica frente al dolor. Job es el hombre que conoce el dolor y anticipa la tradición bíblica desde una perspectiva escatológica, presentando un Mundo real de forma optimista.

Palabras clave: Jerónimo Osório; dolor; comentarios bíblicos; filosofía humanista.

\section{[en] Catholic optimism in front of Baroque pain: Jerónimo Osório's Paraphrasis in $I o b$}

\begin{abstract}
Pain -as well as melancholy-is a baroque sentiment born of a crisis World. Jerónimo Osório, one of the more baroque intellectualist of Portuguese thought, present a biblical figure of Job: the man who knows the pain of the limit World and anticipated in the Biblical tradition the eschatological perspective: the real optimistic World.

Key words: Jerónimo Osório; pain; Biblical Commentaries; Humanism Philosophy.
\end{abstract}

Sumario: 1. Jerónimo Osorio, un teólogo de su tiempo; 2. Explorando el dolor Barroco; 3. La respuesta teológico-exegética de Jerónimo Osório; 3.1. La literatura exegética: los comentarios; 3.2. El Comentario al Libro de Job; 4. Referencias bibliográficas.

Cómo citar: Lázaro Pulido, M. (2019): “Optimismo católico ante el dolor Barroco: Paraphrasis in Iob de Jerónimo Osório”, en Revista Anales del Seminario de Historia de la Filosofía 36 (1), 49-63.

1 Estudio financiado como proyecto del Dep. de Ciencias del Derecho de la Universidad Bernardo O’Higgins (Chile).

2 Manuel Lázaro Pulido

Universidad Nacional de Educación a Distancia, Madrid

Universidad Bernardo O’Higgins, Santiago, Chile

mlazarop@fsof.uned.es

https://orcid.org/0000-0002-0064-5293 


\section{Jerónimo Osorio, un teólogo de su tiempo}

Jerónimo Osório $\left(1515-1580^{3}\right)$ es una de las figuras más importantes del pensamiento portugués ${ }^{4}$. Sus obras fueron publicadas en diversos países en sus 75 ediciones que reflejan una vida forjada de estudio y relaciones personales. Estudió en las grandes universidades europeas de la época. En Salamanca se formó en humanidades llegando a dar clases de iniciación de griego primero $\left(1533^{5}\right)$ para, más tarde, ser catedrático (1548). Allí recibió formación sobre el pensamiento de Aristóteles y se encargó de comentar Las Leyes de Platón ${ }^{6}$. En la Universidad del Tormes adquirió una sólida formación filológica humanista, el contacto con el impulso biblista peninsular -más dependiente de la tradición iniciada en la Universidad de Salamanca por el Tostado y Pedro de Osma que por la hermenéutica de Erasmo-y una preferencia por la ortodoxia teológica como fundamento del pensamiento 7 . Su paso por la Universidad de París (1534-1538 $)^{8}$ se caracterizó por la formación filosófica (dialéctica y filosofía natural) y por tomar contacto con la naciente Compañía de Jesús. Posteriormente perfeccionó sus estudios de teología y se inició en el hebreo en la Universidad de Bolonia (1539$1542)^{9}$. Completó su paso por las aulas universitarias en la Universidad de Coimbra, por entonces el único centro universitario de Portugal, donde fue profesor hasta ocupar la sede episcopal de Silves, en el Algarve portugués.

Jerónimo Osório fue un intelectual que supo dar su opinión en el tiempo que le tocó vivir: el humanismo de la época de la Reforma ${ }^{10}$. Mantuvo una posición marcadamente peninsular, en el sentido en que comprendió que el catolicismo era el nexo de unión y el fundamento de la realidad política del momento ${ }^{11}$. A nivel regional defendió la monarquía luso-española y a nivel europeo el catolicismo como espacio intelectual universal, lo que le llevó a combatir intelectualmente tanto la

3 A través de los datos indicados por Diogo Barbosa Machado en su Biblioteca Lusitana durante mucho tiempo se ha datado el nacimiento de Jerónimo Osório en el año 1506. Nuevas observaciones han establecido la fecha de su nacimiento en 1515. Cf. D. B. Machado, Bibliotheca Lusitana Historica, Critica, e Cronologica, Ignacio Rodrigues, Lisboa 1747, p. 510; A. G. Pinto, "Introdução", en Jerónimo Osório, Opera Omnia I. Paráfrases a Job e à Sabedoria de Salomão, intr., trad. e not. A. Guimarães, Imprensa da Universidade de Coimbra Universidade do Algarve, Coimbra 2009, p. 9.

4 Muestra de su importancia es la presencia de su obra en la Universidad de Oxford, tal como señala el estudio de Thomas F. Earle, "Portuguese Scholarship in Oxford in the Early Modern Period: The Case of Jerónimo Osório (Hieronymus Osorius)", Bulletin of Spanish Studies: Hispanic Studies and Researches on Spain, Portugal and Latin America, 81 (2004) 1039-1049.

5 Seguimos la datación propuesta por António Guimarães Pinto. A. G. Pinto, "Introdução", pp. 5-26.

6 "Perfecisti, vt intra vnius anni spatium Athenas inuiserem, et illos summos doctrinarum omnium principes (...) si sum in Aristotelis disciplina, cum nonnulla ingenii laude versatus, si Platonis amplitudinem suspicere clare potui, si ausus aliquando fui Demosthenis vim mihi ad imitandum proponere, tu certe huius nostri ardoris auctor exstitisti”. Jerónimo Osório, Opera Omnia, Georgius Ferrarius, Roma 1592, I, col. 1173.

7 J. V. Serrão, Portugueses no Estudo de Salamanca (1250-1550), Revista da Faculdade de Letras, Lisboa 1961, pp, 178-181. Sobre la movilidad de los portugueses en aquellos tiempos cf. S. T. Pinho, "A mobilidade dos universitarios e dos quadros nacionais e estrangeiros”, en História da Universidade em Portugal 1573-1771, Universidade de Coimbra-Fundação Calouste Gulbenkian, Coimbra - Lisboa 1997, vol. 1, t. 2, pp. 989-1014.

8 Cf. L. de Matos, Les Portugais à l'Université de Paris entre 1500 et 1550, Universitatis Conimbrigensis Studia ac Regesta, Coimbra 1950.

9 Cf. A. D. S. Costa, "Estudantes portugueses na Reitoria do Colégio de S. Clemente de Bolonha, na primeira metade do século XV", Arquivos de História da cultura Portuguesa, 3 (1970) 1-157.

10 Cf. F. G. Aubrey Bell, "The Humanist Jeronymo de Osorio", Revue Hispanique, 73 (1928) $525-565$ (O Humanista Dom Jerónimo Osório, Imprensa da Universidade, Coimbra 1933).

11 Cf. F. Elias de Tejada, "Las doctrinas políticas de Jerónimo Osorio", Anuario de historia del derecho español, 16 (1945) 341-388. 
teoría ético-política de Maquiavelo ${ }^{12}$, como reflejo de una lectura del humanismo inmanente, como el proyecto religioso y teológico de Martín Lutero.

El obispo de Silves encarna los valores intelectuales de la época, marcados por el prestigio social de la labor intelectual del "teólogo" y por la renovación teológica ${ }^{13}$. El "teólogo" es un intelectual capaz de enfrentar las problemáticas que afectan a los hombres de su época. Se erige como voz autorizada en orden a la salvación de la vida del ser humano en sus realizaciones personales y sociales.

Por su parte, el siglo XVI es un siglo que supone un cambio en la metodología que impulsa la creación teológica ${ }^{14}$. Los teólogos del siglo XV -como el Tostado y Juan de Segovia- promueven el estudio teológico sistemático con la entrada de Aristóteles y el Humanismo en Teología ${ }^{15}$, superándose, así, el verbosismo mediante la introducción de la crítica textual, como es el caso de Martínez de Osma ${ }^{16}$ y los biblistas complutenses ${ }^{17}$. A ello se le suma la renovación del método teológico que armoniza las fuentes reveladas, la razón, la historia, las fuentes de los concilios, las autoridades y doctrinas filosóficas... Esto se concretará en los comentarios de la primera distinción del Libro de las Sentencias de Pedro Lombardo y de la primera cuestión de la Primera Parte de la Suma Teológica de Tomás de Aquino, hasta llegar a los tratados sistemáticos, como es el caso de la obra De locis theologicis de Melchor Cano $(1563)^{18}$.

Jerónimo Osório es, pues, ejemplo del papel del teólogo y la teología del siglo XVI. Su pensamiento es un paradigma del impulso teológico que viene acrecentado por la situación de cambio que se está operando en Europa: una variación de ejes geográficos (del mediterráneo hacia el atlántico y el pacífico), mentales (de la exégesis metafísica a la exégesis humanista), teológicos (del Comentario a la Summa), espirituales (del obrar externo al intimismo), eclesiológicos (de la Iglesia cristiano-católica de la concordia a la Iglesia cristiana de la interpretación), etc.

12 Cf. el capítulo "Osorio and Machiavelli: From Open Hostility to Covert Approbation”, en S. Anglo, Machiavelli - The First Century: Studies in Enthusiasm, Hostility, and Irrelevance, Oxford University Press, Oxford - New York 2005, 143-163.

13 B. Plans, La Escuela de Salamanca y la renovación de la Teología en el siglo XVI, BAC, Madrid 2000.

14 Cf. M. Andrés, La Teología española en el siglo XVI, 2 vols. BAC, Madrid 1976.

15 Cf. J. L. Castillo, "El humanismo de Alfonso de Madrigal, El Tostado, y su repercusión en los maestros salmantinos del siglo XV", Revista Cuadernos Abulenses, 7 (1987) 11-21; A. Cebeira, "La Escuela Humanista Salmantina: Pedro Martínez de Osma, discípulo de El Tostado", La Coronica, 30 (2004) 53-65; C. Flórez, "El humanismo cívico castellano: Alonso de Madrigal, Pedro de Osma y Fernando de Roa", Res publica: revista de la historia y del presente de los conceptos políticos, 18 (2007) 107-140.

16 Cf. M. Andrés, "Antiverbosismo en Pedro Martínez de Osma”, Celtiberia, 30 (1980) 131-138; D. Gonzalo, "La escriturística en la vida y obras del maestro Pedro Martínez de Osma”, Celtiberia, 30 (1980) 117-129; H. Santiago, K. Reinhardt, Pedro Martínez de Osma y el método teológico: Edición de algunos escritos inéditos, Centro de Estudios Sorianos, Soria 1987; J. L. Fuertes, "Contra el nominalismo. Humanismo y renovación de la filosofía y teología en Pedro de Osma", Revista Española de Filosofía Medieval, 11 (2004) 243-255; J. L. Fuertes, F. Panchón, "Pedro Martínez de Osma: Respuesta a algunos disparates de dos verbosistas de esta época”, Revista Española de Filosofía Medieval, 11 (2004) 311-314;

17 Cf. I. Carbajosa - A. García (eds.), Una Biblia a varias voces. Estudio textual de la Biblia Poliglota Complutense, Ediciones San Dámaso, Madrid 2014

18 Melchor Cano, De locis Theologicis libri duodecim, Matías Gast, Salamanca 1563 (nueva edición y traducción en Melchor Cano, De locis theologicis, ed. J. Belda, BAC, Madrid 2006). 


\section{Explorando el dolor Barroco}

Jerónimo Osório muere el año 1580, cuando se establece la Unión Ibérica, expresión política del Barroco peninsular. El obispo-teólogo fue protagonista de los años previos a la nueva situación política entre España y Portugal. En vida conoció la tensión entre la tradición nacional y la posición ibérica que se vivirá en el periodo que va de 1580 a 1648 . Del mismo modo que en la cuestión política, Jerónimo Osório, teólogo humanista de la Reforma, anticipa en sus reflexiones teológicas las cuestiones barrocas. Esto supone que explorar la dimensión filosófico-teológica del pensamiento barroco pasa por indagar sus problemáticas previas y conocer el pensamiento de los intelectuales que los antecedieron -entre ellos nuestro autor-, especialmente en lo referente a la extensión de las ideas contrarreformistas.

En el Siglo de Oro peninsular se hunden las raíces del pensamiento barroco que tuvo en sus primeros pasos un marcado carácter humanista, como muestra la gran obra de la literatura española El Quijote, en la que aparece la transformación de la tradición crepuscular a la perspectiva del nuevo horizonte barroco, desde la hermenéutica metodológica del humanismo ${ }^{19}$. Se pasa de un realismo seguro a un idealismo tan ilusionante como incierto; un idealismo -conceptual- que llevará a los hombres del siglo XVII a vivir su existencia cotidiana, real, de una forma alejada al ideal salvífico de la ilusión humana, acompañado de un sentimiento desgarrado. Se trata de un "anticipo del barroco" que puede también observarse -y que tanto influyó en el pensamiento lusitano- en la cumbre literaria de As lusíadas de Camões ${ }^{20}$.

El dolor anunciado en un tiempo dominado por un pensamiento humanista, se convertirá en el dolor expresado en el barroco del siglo XVII ${ }^{21}$. Quevedo señala en su obra -describiéndola o burlándose de ella- el desengaño, la presencia del dolor y la muerte ${ }^{22}$. Este dolor lo intenta comprender cristianamente Calderón de la Barca: "los personajes que habitan el vasto mundo calderoniano de tragedias, dramas, comedias y autos - escribe María Alicia Amadei-Pulice- tienen esto en común: se deshacen en lágrimas, se subliman en ecos, se lamentan y gritan convulsionados de dolor"23. No serán ajenas a este dolor barroco otras manifestaciones artísticas. Así, la pintura religiosa del siglo XVII manifiesta la presencia del dolor en la vida del cristiano. Los cuadros de Zurbarán muestran la expresión pictórica del dolor limpio, el dolor de la entrega. El dolor se convertirá, de esta forma, en expresión emotiva de la reflexión teológica existencial, así lo expresará Charles Le Brun en su conferencia sobre la

19 J. L. Fuertes, El discurso de los saberes en la Europa del Renacimiento y del Barroco, Ediciones Universidad de Salamanca, Salamanca 2012, p. 267.

20 C. González, "El barroco en Portugal”, en P. Aullón de Haro, Barroco, Verbum Editorial, Madrid $2013^{2}$, p. 750.

21 Sobre las pasiones en el Barroco y la Edad Moderna cf. el vol. 7 de la revista Cauriensia. Señalamos algunos trabajos como J. L. Fuertes, "Entre la transfiguración y la física de las pasiones (1616-1649)", Cauriensia, 7 (2012) 185-238; F. González, "La rehabilitación del mundo emocional en la modernidad. Los predecesores de la ética cartesiana. El estoicismo moderno”, Cauriensia, 7 (2012) 239-248; R. Lázaro, "Descartes y las pasiones humanas", Cauriensia, 7 (2012) 249-257. Trabajados publicados también en el libro M. Lázaro, J. L. Fuertes, Á. Poncela (Eds.), La filosofía de las pasiones y la Escuela de Salamanca, Instituto Teológico de Cáceres (UPSA), Cáceres 2013. Cf. también sobre las pasiones en la época barroca: J. L. Fuertes, M. Lázaro, Ma . I. Zorroza, (Eds.), Pasiones y virtudes en la época del Greco, Eunsa, Pamplona 2016.

22 P. Otaola, Coordenadas filosóficas del pensamiento de Quevedo: obras filosóficas y satírico-morales, Editorial Club Universitario, San Vicente (Alicante) 2004, pp. 103-108.

23 M. A. Amadei-Pulice, Calderón y el Barroco. Exaltación y engaño de los sentidos, Amsterdam-Philadelphia, Benjamín Publishers, 1990, p. 63. 
expresión de las pasiones señalando la expresión corporal del dolor que acompaña a la tristeza ${ }^{24}$. Pedro Cerezo Galán afirma:

A partir del Renacimiento una ola de melancolía se expande por Europa hasta alcanzar su cima en el Barroco. Para explicar este hecho, aparte de la lógica interna del problema... habría que tener en cuenta las condiciones traumáticas de la época. La profunda crisis religiosa con que se inaugura la modernidad, con la tensión entre reforma y Contrarreforma, y la no menor tensión entre los nuevos planteamientos seculares y la creencia religiosa, determinan un tiempo de prueba ${ }^{25}$.

Tras estas manifestaciones artísticas del dolor se levanta una voz teológica. El hombre barroco vive a Dios de forma cercana. Su presencia trascendente se vuelve inmanente en la vida cotidiana del ser humano. El hombre vive religado a Dios. En el cristianismo católico, lo humano y lo divino concurren en un cauce unitario. La vivencia del Dios personal en el mundo se manifiesta a través de su poder en el tiempo del hombre, en la historia. La historia tiene como protagonista a Dios y a los hombres. Los factores que transcurren en la vida del hombre no son el azar o la fortuna, como señalaba Maquiavelo, sino los que nacen de la presencia de Dios en la historia de los hombres entendida como historia de la salvación. Dios creador y omnipotente acompaña al hombre de forma providente. En el catolicismo barroco no existe, por lo tanto, la seguridad humana de la salvación del justo o la desconfianza total en el pecador. El hombre no es el absoluto gestor que pudiera derivarse de una cierta lectura del humanismo, pero tampoco es un in-capax Dei, sino que está en camino, en cuanto homo faber. El hombre no es ajeno a su liberación, tiene capacidad de Dios (capax Dei). El concilio de Trento presenta en la famosa sesión VI una teología de la gracia frente a la teología de la justificación que define el luteranismo y la teología protestante. El Concilio valoró el poder positivo de la gracia y sus frutos en el alma, pero no clarificó de forma suficiente la relación existente entre la naturaleza humana y la gracia, ni tampoco la relación de esta con la libertad. Esta falta de definitivas soluciones teológicas suscitaron lo que conocemos como la controversia "De auxiliis" (1563-1617) ${ }^{26}$. Las respuestas no pondrán en duda la doctrina conciliar, pero sus matices afectarán al modo en el que se entenderán las emociones y las pasiones humanas en la medida en que afectan a la relación del hombre con Dios y su intervención en la vida humana. No es lo mismo subordinarse causalmente a Dios, defendiendo la trascendencia Divina y la dependencia del libre arbitrio -como en el caso de los dominicos-, que operar concausalmente desde la libertad con Dios como es el caso de los jesuitas-. Ni afecta de la misma forma la omnipotencia Divina que conoce los actos humanos ante praevisa merita que aceptar la omnipotencia en el conocimiento de los futuribles (la ciencia media de Molina $^{27}$ ).

24 Ch. Le Brun, L'expression des passions et autres conférences. Correspondence, ed. J. Philippe, CNRS, Paris 1994.

25 P. Cerezo, "Las figuras quijotescas de la melancolía", en F. Duque, J. Chamorro, C. Weller, El yo fracturado y las figuras del Barroco, Círculo de Bellas Artes, Madrid 2006, p. 222.

26 Una síntesis en J. L. Illanes; J. I. Saranyana, Historia de la Teología, BAC, Madrid 2002, pp. 144-152.

27 Luis de Molina, Concordia de liberi arbitrii cum gratiae donis, divina praescientia, praedestinatione et reprobatione, 4 vols., Antonio Ribeiro, Lisboa 1588 (ed. crítica: Luis de Molina, Liberi arbitrii cum gratiae donis, divina praescientia, providentia, praedestinatione et reprobatione concordia, ed. J. Rabeneck, Collegium Maximum S. I., Oña - Madrid 1953). 
En ese contexto, la redención humana entiende el sufrimiento de Jesús como la expresión de la determinación voluntaria y la decisión eterna de Dios como el misterio del amor divino. El padecimiento y muerte de Cristo se entiende desde la glorificación de Cristo y el dolor no tiene únicamente connotaciones negativas, sino que aparece como signo de la gloria. La teología católica de la Cruz lleva a la identificación de Cristo con la cruz como signo de liberación. La expresión ibérica del Viernes Santo, en su magnificencia no termina con el sentimiento vivido en "la procesión del silencio", sino con la alegría y la fiesta del domingo de Resurrección.

\section{La respuesta teológico-exegética de Jerónimo Osório}

\subsection{La literatura exegética: los comentarios}

Lutero pretendía ubicar el humanismo antropocéntrico con el fin de ensalzar la importancia de la fe, su primado absoluto en la vida religiosa humana. La divisa luterana: "sola gratia, sola fides, sola scriptura, solus Deus" indica una primacía de Dios a la que no debería añadirse nada ${ }^{28}$. En la Teología de la Cruz, la humanidad de Cristo queda aminorada. "No es la humanidad de Cristo la que ha vencido al pecado y a la muerte por el hecho de haberse hecho objeto de la maldición divina, sino la divinidad velada en la larva de su humanidad, que Lutero paraleliza con la relación que guardan fe y obras", afirma Adolfo González Montes ${ }^{29}$. Y junto a la humanidad de Cristo, aparece la humanidad de la especulación teológica que aparta al hombre de la Escritura que es Palabra de Dios. Parecería que la metodología teológica católica viviera de espaldas a la Sagrada Escritura, sin embargo nada de eso sucedía, al menos, en la Península Ibérica.

Como hemos señalado, en este contexto general de cambio y apertura teológica iniciada ya en el siglo XV, existe un intento de elaborar una teología positiva en el sentido de realizar una vuelta a las fuentes: la Sagrada Escritura y los Santos Padres, precisamente con la pretensión de superar el verbosismo de un escolasticismo teológico y filosófico decadente. Así se explica que abundaran en el siglo XVI los comentarios bíblicos, como signo de la riqueza que vive la exégesis bíblica en la Península Ibérica. Esta exégesis tiene como base una importante herencia judía $-\mathrm{y}$ con ello de sus escuelas hebraicas-, así como la tradición que existía en la Universidad de Salamanca a raíz de la cátedra de Biblia y de lenguas orientales. Melquiades Andrés señala cinco elementos que en esta época afectan a la historia de la exégesis española peninsular: "la edición de la Políglota de Alcalá, la creación de cátedras de lenguas clásicas y orientales que afectan a la preparación del profesor de Sagrada Escritura y Teología, la transmisión de la exégesis judía a la española, el encuentro entre hebraístas y escolásticos en Salamanca (1570-1581) y, finalmente, la profusión de magníficos comentarios bíblicos, metodológicos y tratados de hermenéutica" ${ }^{30}$.

Dentro de esta tarea exegética, el Libro de Job tiene un significado especial. No

\footnotetext{
28 G. Colzani, Antropología teológica, Secretariado Trinitario, Salamanca 2001, 255.

29 A. González, Reforma luterana y tradición católica. Naturaleza doctrinal y significación social, Universidad Pontificia de Salamanca, Salamanca 1987, 180.

30 M. Andrés, Historia de la teología española. Fundación Universitaria Española, Madrid 1983, p. 634.
} 
tanto porque sea un libro comentado de forma prolífica, más bien al contrario, no tenemos testimonios documentales de muchos comentarios, sino por cuanto era un texto comentado desde la óptica de la teología espiritual, más que desde una óptica exegética. Efectivamente, podemos citar a diversos autores como Cayetano, Titlemann, o los peninsulares Luis de Alcázar, Cipriano de la Huerga, Fernando Jarava, Fr. Luis de León, Juan de Pineda y Jerónimo Osório ${ }^{31}$, entre quienes realizan un comentario a uno de los libros que había sido comentado ya por San Gregorio en sus Morales, obra que había sido traducida a lengua vernácula en ese tiempo por Alonso Álvarez de Toledo ${ }^{32}$ y en la que el Padre de la Iglesia manifestaba la complejidad de esta primera obra de los libros sapienciales.

El editor portugués de la obra de Jerónimo Osório, António Guimaraes, señala que estas obras tienen unas características especiales que hacen que su perspectiva primordial sea más literario-cultural que teológica ${ }^{33}$. Pero esto no anula su interés teológico, en cuanto que el libro de Job afronta un tema que cuestiona la estructura de la fe del hombre: la posición creyente ante el problema del sufrimiento y del dolor. Precisamente, es esta temática compleja, la que puede explicar, también, el hecho de que no existan demasiados tratados sobre este libro de la Escritura. No obstante, la situación doctrinal provocada especialmente por la crisis del luteranismo impulsa algunos comentarios al libro de Job significativos, como el de Jerónimo Osório publicado en 1579, que supondrán lectura obligada para los autores del Barroco del siglo XVII.

En un siglo de crisis, como es el siglo XVII, donde el tema del dolor aflora de forma especial, el libro de Job puede dar una respuesta a la búsqueda de la fortaleza de ánimo para afrontar los momentos difíciles. Quevedo lo utiliza ${ }^{34} \mathrm{y}$, especialmente, los predicadores acuden a este libro como apoyo en su intento de responder a las calamidades individuales y colectivas que se padecen. El sufrimiento se inserta en el misterio divino y desde él se acepta lo incomprensible: calamidades sociales, derrotas en la guerra, etcétera.

En las predicaciones se mantiene por una parte la retribución terrena, aunque de forma débil, y la afirmación del imperio final de la justicia divina después de la muerte. En este aspecto participa de la incomprensión del dolor del justo, pero con la respuesta de la retribución eterna. Se profundiza sobre la responsabilidad personal, aunque sin olvidar la solidaridad del género humano por la que se sufren los pecados del colectivo social. En este sentido es lógico que aparezca ligada a esta explicación la figura de Job. Él es el justo sufriente en quien se personifica la incomprensión del dolor, a pesar de ser inherente a la condición humana. Job es el paradigma de la paciencia y de la aceptación sin caer en la desesperación de una situación difícil y dolorosa. Se trata de un comportamiento que es fruto de la fidelidad a Dios. Job es el paciente y el fiel que confía en la justicia divina, aunque no entienda el porqué. El

31 Cf. las recopilaciones: Nicolás Antonio, "Sacrae Scripturae Interpres. In Job", in Bibliotheca Hispana Vetus, sive Hispanorum, qui usquam unquamve scripto aliquid consignaverunt, notitia. Completens scriptores omnes qui ab Octaviani Augusti imperio usque ad annum M. Floruerunt, ex typographia Antonii de Rubeis, Romae 1696, vol. II, pp. 537-38; F. Vigouroux, Dictionnaire de la Bible, Letouzey et Ané, Paris 1912, Vol. VI, pp. 155979; L. Alonso Schökel y J. Sicre, Job. Comentario teológico y literario, Ediciones Cristiandad, Madrid 1983.

32 Alonso Álvarez de Toledo, Los Morales de Sant Gregorio papa, doctor de la Santa Yglesia, Sevilla 1527 (colofón).

33 P. 59

34 V. García de la Concha, "Quevedo exégeta y moralista: Comentario y discurso sobre el Job", en Id. (ed.), Homenaje a Quevedo, Universidad de Salamanca, Salamanca 1982, p. 188. 
libro de Job recibe a nivel de referencias un tratamiento bastante significativo en el siglo XVII. Así, por ejemplo, en la oratoria barroca sevillana de este siglo un 10,15\% del total de las citas de los libros sapienciales son del libro de $\mathrm{Job}^{35}$, teniendo en cuenta que la literatura sapiencial supone un $42,41 \%$ del total de las referencias ${ }^{36}$.

\subsection{El Comentario al Libro de Job}

Jerónimo Osório, conocido como el "Cicerón portugués", era un reconocido humanista, pero era un humanista católico. Representaba un tipo de humanismo que deja su huella en las interpretaciones exegéticas en las que, por ejemplo, se intentarán equilibrar las lecturas hebraístas y escolásticas de la Biblia. Es una exégesis capaz de romper las tensiones existentes entre el literalismo y el alegorismo al modo de Grajal, Luis de León, Cantalapiedra y Arias Montano, pero con mayor prudencia y menor tensión. En este sentido, Jerónimo Osório pretende usar el dominio humanista para esclarecer, en este caso, las difíciles sentencias que el Libro de Job entrañaba para los biblistas de la época, tal como Diogo de Paiva de Andrade reconoce al biblista español Benito Arias Montano ${ }^{37}$. Efectivamente, Jerónimo Osório Junior en el prefacio señala el carácter filosófico del comentario teológico que aparece en el libro de Job. Y es que el libro de Job, por la naturaleza del propio personaje, y por las circunstancias existenciales y antropológicas que rodean su narración, daba lugar a que fuera ocasión de reflexión filosófico-teológica, en un tratamiento global de la existencia humana, nada más y nada menos que en torno a la vivencia del mal (o del cúmulo de males). Y, así, la posibilidad de recuperación frente a los males en la vida, a partir de una vida virtuosa. Esto es, la posibilidad de la redención humana como un universal espacio-temporal, que prepara la capacidad redentora intrínseca del hombre creado como anticipo de la redención de Cristo.

Desde el principio de la obra el autor señala la referencia filosófico-teológica del Comentario al libro de Job. En el prefacio se afirma:

Platón, el varón más sabio de toda Grecia, como tenía conciencia de que el hombre no fue hecho al azar, sino por deliberación divina, sustentó con mayor sensatez que el hombre, aunque sea atormentado por dolores terribles, vejado por ultrajes y, en fin, rodeado de toda clase de males, incluso así puede ser feliz e puede estar provisto de los ornamentos de las virtudes ${ }^{38}$.

Líneas más tarde, casi repite la expresión. Efectivamente se dice que:

35 M. A. Núñez, La oratoria sagrada de la época del barroco. Doctrina, cultura y actitud ante la vida desde los sermones sevillanos del siglo XVII, Universidad de Sevilla, Sevilla 2000, p. 111.

36 Ibid., p. 104.

37 Cf. D. De Paiva de Andrade, Antologia, ed. A. Guimarães, Esfera do Caos, Lisboa 2011.

38 "Multo quidem prudentius Plato, uir totius Graeciae sapientissimus, cum non casu, sed diuino consilio, hominem ita fuisse informatum perspiceret, eum, etsi grauissimis sit doloribus affectus, contumeliis uexatus, omnibus denique malis circumsaeptus, uirtutum tamen ornamentis circumfluere et beatum esse posse disseruit. In aerumnis enim et summis cruciatibus uirtutis splendor magis elucet, nam dolores et cruciamenta ob imbecillitatemque naturae lacrimae immissae et tristes querimoniae, officium non frangunt, sed constans et excellens in officio seruando animi studium manifeste declarant". Jerónimo Osório, Paráfrases a Job, Praef., 4, p. 67. 
Fue en verdad extraordinario Job, que no solo mostró muy bien que la condición de la naturaleza humana está sujeta a innumerables males, sino que también demostró que en ella se pueden contener los ornamentos de todas las virtudes más elevadas ${ }^{39}$.

Jerónimo de Osório nos sitúa en el marco polémico de la reflexión antropológica que el comentario quiere señalar y manifiesta la profunda controversia teológica que aquí se está discutiendo y que gira en torno a la propia cuestión redentora: en el hombre existen males, pero en él se da también el bien. Esta es una afirmación que prefigura el acontecimiento redentor de Cristo. Jesucristo, como Job lo anticipara, también estuvo rodeado de males y sufrimientos para realizar su acción redentora. Cristo que es el soberano de todas las cosas. Encarnándose toma la forma humana, es decir, una naturaleza débil, e incluso asume el propio mal. Cristo realiza desde la sabiduría de la Providencia del amor de Dios, lo que ya había prefigurado Job y lo que racionalmente estableció Platón. En primer lugar, significa que la presencia del mal no supone un envilecimiento de la condición de la naturaleza humana, sino que señala su debilidad natural. En segundo lugar, supone que el mal, fuente del dolor, es la ocasión que tiene el hombre para ennoblecerse, ya que en la debilidad, en las privaciones, en los dolores... la virtud brilla más. Claramente, el Obispo de Silves se sitúa frente a la posición antropológica de Lutero en la que las obras humanas se encuentran manchadas por el pecado.

El hombre de Dios es un hombre que actúa mirando la gloria aún sabiendo que existe el dolor físico y espiritual. La naturaleza de la fe adoptada por el hombre es el lugar de redención y de esperanza escatológica, y es espacio de una anticipada teodicea:

Aunque el cielo se desmorone y la tierra sufra un inmenso temblor y todo lo que veamos sea consumido por un horroroso incendio, de ninguna forma sucumbirá el espíritu del hombre que con ardiente fe se consagró a Dios: por el contrario, cuanto más vea que todo se perturbe y confunda, con más confianza mirará al cielo... Las ayudas del poder celestial aparecen de forma más clara cuando las esperanzas humanas se desvanecen ${ }^{40}$.

El ejemplo de la vida desgraciada de Job coloca al hombre delante de la situación desesperada, donde el refugio de la muerte como fin de los sufrimientos no es la solución. La solución empieza por la propia vida, por reconocer los límites, por abrir nuestra existencia a la "clemencia y ayuda de Dios"41. Pero la ayuda de Dios respeta la voluntad humana y tiene en cuenta, a la vez, la debilidad del hombre:

39 "Mirus profecto fuit iste Iobus, qui et naturae humanae condicionem innumerabilibus malis obnoxiam esse luculenter ostendit, et in ea ómnium maximarum uirtutum ornamenta retineri posse demonstrauit. Quod ut ab ómnibus perspici posset, diuino munere effectum fuit ut tanti uiri historia a Mose, ut aliqui putant, uel, posteaquam Moses e uita discessit, ab aliquo uiro sanctitatis laude florente esset monumentis commendata". Jerónimo Osório, Paráfrases a Job, Praef., 4, p. 67.

40 "Vt igitur caelum ruat, terra ingenti motu tremefacta desideat et omnia, quae intuemur oculis, horribili incendio deflagrent, animus hominis, qui se Deo ardente fide consecrauit, nullo modo concidet: immo, quo magis omnia perturbari et confundi perspexerit, eo confidentius in caelum respiciet et elatius exspectatione praesentissime salutis efferetur. Tunc enim clarius et magnificentius praesidia caelestis numinis afferuntur, cum humanae spes omnes infringuntur". Jerónimo Osório, Paráfrases a Job, Lib. I, Proem., 12, p. 79.

41 "Hoc certe, ut ad Dei clementiam et opem confugiamus". Jerónimo Osório, Paráfrases a Job, Lib. I, Proem., 28, p. 107 
Pero mientras tanto, como es muy difícil evitar el pecado, debe entenderse como bienaventurado no a quien no se protege del castigo que merece su delito, sino a quien, teniendo tiempo para arrepentirse, se le impone una pena que le enseñe a volver al cumplimiento de sus obligaciones.

Por consiguiente, no rechaces el beneficio de esta enseñanza que Dios te concede misericordiosamente. En efecto, si no te muestras desagradecido y reconocen en esos golpes su benignidad, recogerás gran provecho de tu desgracia ${ }^{42}$.

Desde el inicio Jerónimo Osório muestra la perspectiva católica, humanamente positiva, respecto al espíritu luterano. La salud del espíritu y, por lo tanto, la justicia, radica tanto en la fe como en el correlativo desprecio del pecado, acompañado de un sincero arrepentimiento. Dios exige al hombre una verdadera contrición anterior a la concesión de la justicia de la gracia, en contra de lo afirmado por Lutero, para quien la contrición, anterior a la gracia de Cristo, aumenta el carácter pecador del hombre, pues demuestra aún mayor imperfección al mostrar una falta de confianza en la caridad de Cristo.

En la reflexión de Osório se hace presente, ad sensum contrarium la doctrina de la justificación de la Confessio Augustana (homines) gratis iustificentur propter Christum, que implica la exclusión que representa la negación: "homines non possint justificari coram Deo propriis viribus, meritis aut operibus". La lectura de la confesión, de la justificación por la ley, daba lugar a una interpretación donde se da la impresión de que se excluyen las obras y la acción del hombre en el proceso de justificación. En efecto, la confesión se hace eco de la intencionalidad antisemipelagiana de los reformadores en contra de los teólogos escolásticos de la Edad Media tardía, y plantea el debate sobre la relación entre la gracia y el mérito, entre la acción de Dios y la acción del hombre. En este sentido, Osorio plantea una cuestión importante en el propio texto en sí, pero, se trata de una cuestión que se abre a una cierta modernidad que trasciende el texto, en el sentido de que plantea una hermenéutica del equilibrio, en la que, casi de forma ecuménica, busca la justa medida, sin negar el valor causativo de la gracia en la justificación -y la redención humana-. Su interpretación se parece a la actual interpretación del último propósito de la propia afirmación luterana realizada en la Confesión de Augsburgo.

Sin duda, lo que Osório quiere mostrar, a través del Comentario al libro de Job, es el carácter imputativo que parecía plantear la formulación sobre la justificación. Efectivamente, justificarse es "ser tenido por justo", lo que representa la propia historia de Job. Job es un hombre justo que, sin embargo, en su vida parece que no lo es y que "no es tenido por justo" por sus vecinos. Un ejemplo contradictorio que, a veces, pareciera como si fuera la personificación de la justificación por la fe; pero que, a su vez, encierra en la palabra, la apertura a la voluntariedad del hombre en su condición para que la justificación sea más efectiva que indicativa.

Osorio quiere mostrar a los reformadores la exageración de su interpretación de la doctrina medieval expresada en la sentencia: faciendi quod est in Deus non denegat gratiam, donde la gracia es un hábito que en el fondo está atribuyendo al

42 "Interim uero, cum difficillimum sit peccatum uitare, ille beatus habendus est cuius delicto debitum supplicium minime differtur, sed, dum paenitendi tempus est, poena ei, qua eruditus ad officium redire possit, imponitur. Ne igitur hoc disciplinae beneficium, quo te Deus clementer afficit, aspernere. Nam, si te minime ingratum praebueris et in istis plagis illius benignitatem sapienter agnoueris, ingentem ex ista clade fructum percipies". Jerónimo Osório, Paráfrases a Job, Lib. I, Proem., 28, p. 107. 
hombre un protagonismo en la acción gratuita (justificadora) de la obra de Cristo. La exageración protestante se observa de forma clara en Melanchton cuando añade a la fórmula la expresión per gratiam et fidem. El añadido a la fórmula tradicional (per gratiam) de la fórmula reformada (per fidem) -en relación al solus Christus-, plantea un problema fundamental: el de la eficacia salvífica de las obras en el proceso de justificación. Osorio tiene presente en el comentario la redención del hombre en la doctrina de la justificación escolástica expresada en la fórmula: "justificación por la gracia creada por Dios en el hombre".

Es en este sentido, que podemos entender las líneas con las que se inicia el proemio del libro tercero:

El varón justo y sabio concluyó de esta forma la defensa de su causa de forma fácil, contrariando las palabras de los amigos, defendió su inocencia y probó que no es verdad que de la suerte atribuida a una persona pueda probarse que incurrió en un crimen y evaluar la grandeza de las infamias por el peso de la desgracia. Lo que sucede es que la vida humana es un ejercicio y una lucha, y hasta una actividad e aprendizaje de coraje militar, en la que, a través de los peligros, trabajos y dolores frecuentemente se conoce de forma segura la piedad de los mejores hombres $y$, de este modo, se alcanza el elevadísimo premio de la gloria eterna ${ }^{43}$.

Jerónimo Osório tiene en vista en el comentario la doctrina antropológica subyacente a la comprensión de la justificación de Lutero en la que la obra salvífica de Jesucristo viene apoyada en el hecho de que solo Dios tiene el honor y el mérito del cambio del estatuto antropológico de la persona que es justificada. Jerónimo Osório repara en que la doctrina reformada se apoya en una antropología que actúa sobre la base doctrinal y en la que domina una "protología infralapsaria", con una notable ausencia de la soteriología, es decir, con un olvido del significado escatológico del carácter salvífico.

El dolor tiene una significación que se proyecta desde una visión optimista del mundo sustentada en la doctrina de la redención católica en perspectiva escatológica. Se trata, pues, de una justificación de nivel efectivo, católico, que permite acudir a categorías como la santificación a través de la conversión y transformación internas, de la lectura creyente de los males y dolores espirituales y de la cooperación en la santidad a partir de las oraciones: "Como Job dirigió a Dios oraciones por sus amigos -dice Osório-, Dios hizo las paces con ellos y miró al propio estado atribulado de $J o b$, dándole el doble de los bienes que tenía anteriormente" ${ }^{44}$.

El teólogo portugués propone una justificación apartada del nivel imputativo de la explicación protestante. La historia del dolor de Job nos presenta la importancia del hombre sabio, inteligente y libre, en la acción salvífica de Dios. El dolor del hombre

43 "Causam quidem suam uir iustus et sapiens ita perorauit ut facillime suam innocentiam, contra amicorum orationem, tueretur et ostenderet non esse uerum ex afflicta cuiusque fortuna suscepti sceleris argumentum sumere et pro grauitate calamitatis flagitiorum magnitudinem ponderare. Est enim humana uita ludus et palaestra, atque adeo militaris uirtutis officium et disciplina, in qua periculis et laboribus et doloribus summorum hominum saepenumero pietas explórate cognoscitur, et ita praemium amplissimum gloriae sempiternae consequitur". Jerónimo Osório, Paráfrases a Job, Lib. III, Proem., 91, p. 234.

44 "Por consequência, como Job dirigiu a Deus preces pelos amigos, Deus fez as pazes com eles e olhou pelo atribulado estado do próprio Job e deu-lhe em dobrado uma abundância de todos os bens maior do que a que possuíra anteriormente". Jerónimo Osório, Paráfrases a Job, Lib. III, Proem., 128, p. 305. 
aparece como lugar de creación del espíritu libre. Osório destierra una lectura excesivamente pasiva y conformista en la acción humana a la luz de la Reforma. Job es ejemplo de que la voluntad y las obras humanas cooperan en la acción salvífica divina escapando del determinismo teológico de la doctrina de la predestinación luterana. Para Osório la doctrina de la predestinación luterana asentada en una antropología negativa, como señala en su Tratado de la justicia:

Destruye las leyes, aniquila los entendimientos, hace desaparecer la mente, estropea los sentimientos, corrompe las costumbres y perturba todo el orden de la existencia, pues imputa a Dios, autor de todo los bienes, las causas de los crímenes y lo hace reo de la iniquidad, crueldad y locura ${ }^{45}$.

Desde la perspectiva luterana el dolor presente en el hombre, el mal de culpa y de pena, es consecuencia directa de Dios lo que pervierte su propia esencia amorosa. La predestinación fuerza la providencia divina, de modo que Dios justifica el dolor en las creaturas, cuando en realidad es su verdadero libertador, como sucede en la naturaleza. Osorio pone como ejemplo el parto de las cabras: “¿quién es el que mira por ellas en la aflicción y las libra del dolor? Sin duda que Mi poder divino, que gracias a su providencia lo conserva todo"46.

La bondad de Dios no excluye la responsabilidad humana, la colaboración o falta de colaboración de la gracia creada y con ello de sus consecuencias:

Todas las desgracias humanas, todas las penalidades de la vida, todos los dolores y tribulaciones deben atribuirse al santísimo juicio de Aquel que castiga crímenes humanos con merecida pena ${ }^{47}$.

Así pues, Jerónimo Osório distingue entre las cosas hechas por Dios (voluntad natural) y las toleradas por Él (voluntad deliberativa). Dios realiza las cosas y las hace conforme a su naturaleza: las hace bien. Dios no es autor del mal. Al hombre no solo lo creo bien sino que como consecuencia de ese bien hacer lo hizo libre. Esa libertad fruto de la bondad supone que está en sus manos el aceptar o rechazar su luz y cuidado. La maldad humana no nace de una insondable instrumentalización humana en manos dela omnipotencia divina, tal como la teología luterana parece expresar desde una soteriología hamartiológica. Sino que en su bondad permite la libertad. Su providencia guía y presenta el camino al sabio -"en Dios un rectísimo juicio precede todo lo que hace, per no determina nada en contra de la armonía con la ley y la razón"48 -, pero no predestinada a nadie y menos al justo: “¿Ves que falsa es tu afirmación de que es por voluntad de Dios que le va bien a los perversos y que los inocentes con frecuencia sufren contrariedades?"49.

45 Jerónimo Osório, Tratado de justicia, intr., trad. e not. A. Guimarães, Imprensa Nacional - Casa da Moeda, Lisboa 1996, p. 308.

46 "Quis igitur illas in angustia tuetur et dolore omni liberat? Meum profecto numen, cuius prouidentia omnia conseruantur”. Jerónimo Osório, Paráfrases a Job, Lib. III, Proem., 117, p. 283.

47 "Omnes igitur humanae clades, omnes uitae acerbitates, omnes dolores et aerumnae ad illius sanctissimum iudicium referendae sunt qui scelera humana debito supplicio persequitur”. Jerónimo Osório, Paráfrases a Job, Lib. III, Proem., 106, p. 261.

48 “...siue consiliorum diuinorum rationes exploratae tibi sint, siue non sint, in omnibus illius factis rectissimum iudicium antegredi...". Jerónimo Osório, Paráfrases a Job, Lib. III, Proem., 106, p. 261.

49 "Cernis iam quam sit falsum id quod asserebas: nempe, Dei uoluntate improbis multa feliciter euenire et 
El dolor en Jerónimo Osório no solo no pone en duda la ciencia divina, pues el conocimiento del tiempo pasado, presente y futuro consiste en una pre-visión divina que no implica necesidad en las decisiones humanas. El optimismo está garantizado en la capacidad de cuidado del hombre. Todo hombre está llamado a observar el dolor y enfrentarse al mal, en aras a ver desde esta situación su posibilidad de realización del bien y la capacidad de evitar el mal, cooperando con el acto creador y redentor de Dios y optando definitivamente por el bien. Dios no es positivo de una condición humana, sino propositivo del actuar humano. Por una parte, Jerónimo Osório muestra en el Comentario al Libro de Job el humanismo católico penetrante en la exégesis bíblica. Por otra parte, su doctrina sobre el cuidado y el rectísimo juicio sin determinación, señala su apuesta por la providencia, sobre la predestinación. En el equilibrio entre causalidad y libertad parece que se inclina más por la solución antireformista de la Concordia molinista, que por la posición de Báñez. No obstante, el tema de la doctrina del auxilio de la gracia ya es otra controversia que merecería otra reflexión.

\section{Referencias bibliográficas}

Alonso Schökel, L., Sicre, J. Job. Comentario teológico y literario, Ediciones Cristiandad, Madrid 1983.

Álvarez de Toledo, A. Los Morales de Sant Gregorio papa, doctor de la Santa Yglesia, Sevilla 1527.

Amadei-Pulice, M. A. Calderón y el Barroco. Exaltación y engaño de los sentidos, Amsterdam-Philadelphia, Benjamín Publishers, 1990.

Andrés, M. La Teología española en el siglo XVI, 2 vols. BAC, Madrid 1976.

Andrés, M. "Antiverbosismo en Pedro Martínez de Osma”, Celtiberia, 30 (1980) 131-138.

Andrés, M. Historia de la teología española. Fundación Universitaria Española, Madrid 1983.

Anglo, S. Machiavelli - The First Century: Studies in Enthusiasm, Hostility, and Irrelevance, Oxford University Press, Oxford - New York 2005.

Aubrey Bell, F. G. "The Humanist Jeronymo de Osorio", Revue Hispanique, 73 (1928) 525565 (O Humanista Dom Jerónimo Osório, Imprensa da Universidade, Coimbra 1933).

Cano, M. De locis Theologicis libri duodecim, Matías Gast, Salamanca 1563 (nueva edición $\mathrm{y}$ traducción en Melchor Cano, De locis theologicis, ed. J. Belda, BAC, Madrid 2006).

Carbajosa, I., García, A. (eds.), Una Biblia a varias voces. Estudio textual de la Biblia Políglota Complutense, Ediciones San Dámaso, Madrid 2014.

Castillo, J. L. "El humanismo de Alfonso de Madrigal, El Tostado, y su repercusión en los maestros salmantinos del siglo XV", Revista Cuadernos Abulenses, 7 (1987) 11-21.

Cebeira, A. "La Escuela Humanista Salmantina: Pedro Martínez de Osma, discípulo de El Tostado", La Coronica, 30 (2004) 53-65.

Cerezo, P. "Las figuras quijotescas de la melancolía", en F. Duque, J. Chamorro, C. Weller, El yo fracturado y las figuras del Barroco, Círculo de Bellas Artes, Madrid 2006.

Colzani, G. Antropología teológica, Secretariado Trinitario, Salamanca 2001.

innocentes immeritis saepe incommodis diuexari?’. Jerónimo Osório, Paráfrases a Job, Lib. III, Proem., 108, p. 265. 
Costa, A. D. S. "Estudantes portugueses na Reitoria do Colégio de S. Clemente de Bolonha, na primeira metade do século XV", Arquivos de História da cultura Portuguesa, 3 (1970) $1-157$.

De Paiva de Andrade, D. Antologia, ed. A. Guimarães, Esfera do Caos, Lisboa 2011.

Earle, Thomas F. "Portuguese Scholarship in Oxford in the Early Modern Period: The Case of Jerónimo Osório (Hieronymus Osorius)", Bulletin of Spanish Studies: Hispanic Studies and Researches on Spain, Portugal and Latin America, 81 (2004) 1039-1049.

Flórez, C. "El humanismo cívico castellano: Alonso de Madrigal, Pedro de Osma y Fernando de Roa", Res publica: revista de la historia y del presente de los conceptos políticos, 18 (2007) 107-140.

Fuertes, J. L. "Contra el nominalismo. Humanismo y renovación de la filosofía y teología en Pedro de Osma", Revista Española de Filosofía Medieval, 11 (2004) 243-255.

Fuertes, J. L. El discurso de los saberes en la Europa del Renacimiento y del Barroco, Ediciones Universidad de Salamanca, Salamanca 2012.

Fuertes, J. L. "Entre la transfiguración y la física de las pasiones (1616-1649)", Cauriensia, 7 (2012) 185-238.

Fuertes, J. L., Lázaro, M., Zorroza, Mª I. (Eds.), Pasiones y virtudes en la época del Greco, Pamplona, Eunsa 2016.

Fuertes, J. L., Panchón, F. "Pedro Martínez de Osma: Respuesta a algunos disparates de dos verbosistas de esta época”, Revista Española de Filosofía Medieval, 11 (2004) 311-314.

García de la Concha, V. "Quevedo exégeta y moralista: Comentario y discurso sobre el Job”, en Id. (ed.), Homenaje a Quevedo, Universidad de Salamanca, Salamanca 1982.

González, A. Reforma luterana y tradición católica. Naturaleza doctrinal y significación social, Universidad Pontificia de Salamanca, Salamanca 1987.

González, C. "El barroco en Portugal", en P. Aullón de Haro, Barroco, Verbum Editorial, Madrid 20132, p. 747-775.

González, F. "La rehabilitación del mundo emocional en la modernidad. Los predecesores de la ética cartesiana. El estoicismo moderno", Cauriensia, 7 (2012) 239-248.

Gonzalo, D. "La escriturística en la vida y obras del maestro Pedro Martínez de Osma", Celtiberia, 30 (1980) 117-129.

Illanes J. L., Saranyana, J. I. Historia de la Teología, BAC, Madrid 2002.

Lázaro, M., Fuertes, J. L., Poncela, Á. (Eds.), La filosofía de las pasiones y la Escuela de Salamanca, Instituto Teológico de Cáceres (UPSA), Cáceres 2013.

Lázaro, R. "Descartes y las pasiones humanas”, Cauriensia, 7 (2012) 249-257.

Le Brun, Ch. L'expression des passions et autres conférences. Correspondence, ed. J. Philippe, CNRS, Paris 1994.

Machado, D. B. Bibliotheca Lusitana Historica, Critica, e Cronologica, Ignacio Rodrigues, Lisboa 1747.

Matos, L. de. Les Portugais à l'Université de Paris entre 1500 et 1550, Universitatis Conimbrigensis Studia ac Regesta, Coimbra 1950.

Molina, L. de. Concordia de liberi arbitrii cum gratiae donis, divina praescientia, praedestinatione et reprobatione, 4 vols., Antonio Ribeiro, Lisboa 1588 (ed. crítica: Molina, L. de. Liberi arbitrii cum gratiae donis, divina praescientia, providentia, praedestinatione et reprobatione concordia, ed. J. Rabeneck, Collegium Maximum S. I., Oña-Madrid 1953).

Nicolás Antonio, "Sacrae Scripturae Interpres. In Job", in Bibliotheca Hispana Vetus, sive Hispanorum, qui usquam unquamve scripto aliquid consignaverunt, notitia. Completens scriptores omnes qui ab Octaviani Augusti imperio usque ad annum M. Floruerunt, ex 
typographia Antonii de Rubeis, Romae 1696, vol. II.

Núñez, M. A. La oratoria sagrada de la época del barroco. Doctrina, cultura y actitud ante la vida desde los sermones sevillanos del siglo XVII, Universidad de Sevilla, Sevilla 2000.

Osório, J. Opera Omnia, Georgius Ferrarius, Roma 1592.

Osório, J. Tratado de justicia, intr., trad. e not. A. Guimarães, Imprensa Nacional - Casa da Moeda, Lisboa 1996.

Osório, J. Opera Omnia I. Paráfrases a Job e à Sabedoria de Salomão, intr., trad. e not. A. Guimarães, Imprensa da Universidade de Coimbra - Universidade do Algarve, Coimbra 2009.

Otaola, P. Coordenadas filosóficas del pensamiento de Quevedo: obras filosóficas y satíricomorales, Editorial Club Universitario, San Vicente (Alicante) 2004.

Pinho, S. T. "A mobilidade dos universitarios e dos quadros nacionais e estrangeiros", en História da Universidade em Portugal 1573-1771, Universidade de Coimbra-Fundação Calouste Gulbenkian, Coimbra - Lisboa 1997, vol. 1, t. 2.

Plans, B. La Escuela de Salamanca y la renovación de la Teología en el siglo XVI, BAC, Madrid 2000.

Santiago, H., Reinhardt, K. Pedro Martínez de Osma y el método teológico: Edición de algunos escritos inéditos, Centro de Estudios Sorianos, Soria 1987.

Serrão, J. V. Portugueses no Estudo de Salamanca (1250-1550), Revista da Faculdade de Letras, Lisboa 1961.

Vigouroux, F. Dictionnaire de la Bible, Letouzey et Ané, Paris 1912, Vol. VI.

Tejada, F. Elias de. "Las doctrinas políticas de Jerónimo Osorio”, Anuario de historia del derecho español, 16 (1945) 341-388. 